\title{
Viscusi's Risk by Choice: Regulating Health and Safety in the Workplace
}

\author{
Lester B. Lave*
}

When grey-haired economists sit around the lounge, recounting their heroic deeds to wide-eyed graduate students, one saga will concern the regulation and deregulation of occupational safety:

"We told 'em not to intervene, that federal regulation wouldn't do any good, and would only impose large costs and red tape on employers. Did they listen to us? You can bet they didn't. Those do-gooders filled the pages of the Federal Register. They required employers to buy new toilet seats and replace 29 inch handrails with 30 inch handrails. As we predicted, they held the government up to ridicule, wasted billions of dollars, and didn't improve worker safety by one whit. When all that was painfully clear to everyone, many, many years later, we got them to let the market do most of the job."

Telling the story with relish, although in less colloquial English, Viscusi scores those economically ignorant (politically savvy) do-gooders who won most of the battles when he was Deputy Director of the Council on Wage and Price Stability. Of course, the last act, giving a greater role to market forces, has yet to be written, but this book is intended to be a boost to the process.

\section{The inadequacies of OSHA}

Viscusi is at his best in describing the current and past operations of the Occupational Safety and Health Administration (OSHA), the nature of its regulations, and the reason one should not have expected much of an improvement in worker safety. The chapters are crammed with facts, summaries of the relevant literature, and insightful observations. Viscusi argues that the increase in worker injury rates in the 1960s that stirred attention and led to the creation of OSHA was "a statistical artifact; job hazards actually were continuing to diminish throughout this period, as were other risk levels."

The inadequacies of OSHA inspection are detailed, along with the lack of focus on serious problems and the areas where OSHA could do the most good. The level of fines has been so low that the economic incentive for improving safety is virtually zero.

Viscusi summarizes analyses of how workers perceive and react to occupational hazards. Unions are seen as affecting health and safety by reflecting the average preference of workers, rather than the preferences of those workers who self-selected into the most dangerous jobs. This phenomenon might be used to explain why organized labor invested so much effort in having OSHA created and why the unions support its efforts so strongly - they are limiting competition by workers who are less risk averse and by the nonunion companies who would employ them. The differences in risk aversion are estimated to be large: The average worker (in a job of average, relatively low risk) puts a much higher premium on safety than does a worker who is employed in one of the most

\footnotetext{
* Carnegie-Mellon University.
} 
hazardous jobs. For those at greatest risk, the implicit value of life is on the order of $\$ 500,000$, while it is $\$ 2$ million for the average worker.

Viscusi sees quitting as a major way in which workers, independent of OSHA regulation, can adjust their risk levels and give signals to employers about the optimal risk level of jobs. Given the poor quality of information available to a potential employee, the individual is seen as relying on the reputation of the company and industry in accepting a job. Onthe-job experience gives the worker sufficient information on risk that he can quit and search for a less risky job if the risk is perceived to be unacceptably high.

When Viscusi is presenting economic analyses of OSHA and worker behavior, he is authoritative. It is especially valuable to have the studies about worker perceptions of risk and how they accord with accident statistics. But the translation of this economic research into policy recommendations is less well done.

\section{Pacification or search and destroy?}

- The White House economists went into battle with the regulatory do-gooders but accomplished little: "In almost all instances of RARG [Regulatory Analysis Review Group] interventions, the final regulation was closer to the RARG position than was the initial proposal." This carefully phrased victory claim is that most of the time RARG got at least a sop from the agencies.

While getting agencies to think about costs and benefits probably did some good, the RARG review process was largely a sort of "high noon" duel, with agencies defending their positions and the economists showing how smart they were (Miller and Yandle, 1979). One cannot help remembering the stunning failure when they went to President Carter over OSHA's cotton dust standard and lost. No further battle was seriously contested; they even refused to go to the mat with EPA over the ozone regulation (White, 1981).

Viscusi recognizes (as did White) the importance of the process and approves of agencies hiring their own economists. While this will take away the easy victories in future reviews, the regulations advanced by the agencies should be more sound. It is much easier to influence an agency before the position is formulated than it is after the agency is defending itself.

Viscusi displays, however, a somewhat naive, technocratic view about the goals of government actions: "Even if the issue can be thoroughly explored, there is no assurance that the decision will be motivated by the net social benefits of the regulation rather than by quite different political pressures." Even a narrow definition of economic efficiency exists only within a set of values. More generally, other criteria, such as equity, are the essence of the political process. Politics is precisely the process in which a social consensus on values is hammered out. Economic efficiency (defined within one or more value sets) is but one of the relevant inputs to arriving at a decision.

\section{Regulatory reform}

- Although Viscusi is willing to provide some advice to OSHA in the chapter, "How to Set Standards If You Must," and does not advocate abolishing OSHA, he is opposed to the current approach: "After abolishing the current set of health and safety standards, we should base OSHA policies on the following three elements: (1) provision of risk information to workers, (2) greater merit rating of workers' compensation, and (3) penalties on hazardous firms to promote health and safety for selected risks."

His emphasis is on the first aspect: "A useful starting point might be to require employers to apprise workers of the nature of the risks they face, the risk level of the firm (death, injury, and illness rates), its relative risk compared to [sic] that of other firms in the industry, the possibility of synergistic effects, such as that of asbestos and cigarette 
smoking, and the need for exercising special care." Perhaps, he would write such a report for, say, DuPont. Safety engineering and toxicology could not provide this information. What is currently known could not be understood by many workers.

Most of the chemicals to which workers are exposed have been introduced within the last two decades. As in the case of those who contracted angiosarcoma from exposure to vinyl chloride monomer, the period between first exposure and presentation of the disease is a matter of decades. There are roughly 60,000 chemicals in common use in the United States (Lave, 1983). Surely, many of them either enhance or dampen the effects of other chemicals in more than additive fashion. Toxicologists classify carcinogens as initiators or promoters (defining one type of nonlinear interaction among chemicals). Few of the 60,000 chemicals have been tested for carcinogenicity, much less for their classification as initiators or promoters. Surely, some of the chemicals will affect reproduction by being mutagens, diminishing fertility, or affecting the development of the fetus. Providing information, even to a worker with a $\mathrm{Ph} . \mathrm{D}$. in toxicology, is not simple. For the foreseeable future, such information could not help but be incomplete.

Viscusi's second recommendation is to have employers' premiums for workers' compensation calculated essentially on the basis of individual experience. He is concerned that small firms could be bankrupted by a single stroke of "bad luck" and so modifies the self-insurance aspect slightly.

Bringing home the incentives for safety to each employer is a good idea, but there are two more important problems with workers' compensation: (1) inadequate payments to workers and (2) the difficulty in dealing with chronic disease. In most states the awards are so small that disgruntled workers seek further compensation. Judges and juries have sympathized with their plight and have awarded compensation from equipment makers and chemical suppliers, since workers cannot sue their employers. For example, the Manville Corporation is in bankruptcy not because of compensation payments to its workers, but because of suits of employees of other firms that used Manville asbestos. Unless awards are perceived to be equitable, judges and juries will find some "deep pocket" to compensate injured workers.

A reformed system for workers' compensation might handle injury. As Viscusi recognizes, though, it seems inconceivable that it would handle occupational disease, at least at the current state of knowledge (Lave, 1981). Any injury taking place on the plant site is assumed to be occupationally caused, even if it results from a lunch-time football game. However unjust this seems, the time at the plant site is limited, and the employer can watch over football games as well as over dangerous machines.

In contrast, consider a worker with lung cancer who has a known predisposition toward cancer (his parents and siblings died of cancer), who smokes more than two packs of cigarettes each day, who during World War II installed asbestos in a shipyard, who then installed asbestos in buildings, and who now works for a different company in a building with asbestos flaking off the ceiling. What is the cause of the lung cancer? Who should pay compensation? His current employer might be forgiven for his reluctance to dig into his experience-rated insurance fund to pay compensation.

Almost all people develop chronic diseases as they age. As in the example, the diseases are caused or aggravated by multiple factors. At the current state of knowledge, separating the contribution of occupational factors is generally impossible. But even suppose one knew: (1) the disease would not have appeared for five more years without occupational exposure; or (2) the disease would have been $10 \%$ less severe without the occupational exposure; or (3) 40 of 100 similar men with the same occupational exposure would be expected to develop the disease compared with 35 of 100 who did not have the occupational exposure. Even supposing epidemiologists could make a statement such as (1), (2), or (3), it would be far from trivial to determine how much compensation should be paid. Insurance companies do not compensate a widow with the expected value of her husband's insurance. 
I also have a serious difference with Viscusi concerning the interests of society beyond the employer's and worker's self-interest. He writes, "I am not advocating such an injury tax here because there is little evidence that there is a significant inadequacy in the manner in which market forces promote safety." Safety is the sum of the care taken by employer and employee. Experience rating plus large awards to injured employees will motivate employers to increase safety. But employees will be less motivated. Low awards would have the opposite effect. An injury tax produces a wedge between the incentives to employer and employee that would bring the two closer to society's preferences.

In the third aspect of his regulatory reform, Viscusi suggests that market interventions may sometimes be necessary. This "component of the policy is intended to address the instances in which a market process in conjunction with greater risk information will not generate efficient risk levels. In these exceptional circumstances, which should pertain almost exclusively to dimly understood health risks, OSHA should consider additional forms of intervention." Biological monitoring for toxic substances and medical surveillance for acute disease known to precede more serious chronic disease are helpful, as Viscusi suggests. Where applicable, they can allow disease risks to be treated similarly to injuries. When they are not possible, however, and the time between first exposure and manifestation of the disease is several decades, I doubt that either workers or employers would display much concern, and without adequate monitoring techniques, it is difficult to see how penalties could be imposed. This is a good example of a situation where both workers and employers are likely to be more myopic than society is.

This is not the definitive book on OSHA, but it has much to say and musters the evidence well. It is a step toward that definitive book.

\section{References}

LAVE, L.B. The Strategy of Social Regulation: Decision Frameworks for Policy. Washington: Brookings Institution, 1981.

- Quantitative Risk Assessment in Regulation. Washington: Brookings Institution, 1983.

Miller, J.C., III AND YANDLE, B., EDS. Benefit-Cost Analyses of Social Regulation: Case Studies from the Council on Wage and Price Stability. Washington: American Enterprise Institute, 1979.

VISCuSI, W.K. Risk by Choice: Regulating Health and Safety in the Workplace. Cambridge: Harvard University Press, 1983.

WHItE, L.J. Reforming Regulation: Processes and Problems. Englewood Cliffs, N.J.: Prentice-Hall, 1981. 